\title{
Pengaruh Penerapan Manajemen Berbasis Sekolah terhadap Mutu Pendidikan: Studi Kasus di SDIT Al-Haraki Kota Depok
}

\author{
Abu Maskur \\ Universitas Indraprasta PGRI Jakarta, Indonesia \\ masykur_azizi@yahoo.co.id
}

doi DOI: 10.37542/iq.v4i01.196

\begin{abstract}
This study aims to determine the effect of implementing school-based management (SBM) on the quality of education at SDIT Al-Haraki Depok City. The method used in this research is quantitative, namely the data obtained in the form of numbers and the analysis emphasizes numerical processing with statistics. The approach used in this research is correlational which aims to see the effect of the implementation of school-based management on the quality of education. The results obtained from this study state that there is a positive and close influence between the implementation of school-based management (SBM) on the quality of education at SDIT Al-Haraki Depok City which is indicated by the correlation coefficient value $r=0.464$, it can be obtained the determination $\mathrm{R} 2=0.215$, which means that the implementation of school-based management (SBM) has contributed $21.5 \%$ to improving the quality of education at SDIT Al-Haraki.
\end{abstract}

Keywords: School-Based Management, Quality of Education, Integrated Islamic Elementary School

\begin{abstract}
Abstrak
Penelitian ini bertujuan untuk mengetahui pengaruh penerapan manajemen berbasis sekolah (MBS) terhadap mutu pendidikan di SDIT Al-Haraki Kota Depok. Metode yang digunakan dalam penelitian ini adalah kuantitatif, yakni data yang diperoleh berupa angka dan analisisnya menekankan pada numerikal yang diolah dengan statistika. Pendekatan yang digunakan dalam penelitian ini adalah korelasional yang bertujuan untuk melihat pengaruh antara penerapan
\end{abstract}


manajemen berbasis sekolah terhadap mutu pendidikan. Adapun hasil yang diperoleh dari penelitian ini menyatakan bahwa ada pengaruh positif dan erat antara penerapan manajemen berbasis sekolah (MBS) terhadap mutu pendidikan di SDIT Al-Haraki Kota Depok yang ditunjukkan dengan nilai koefisien korelasi $\mathrm{r}=0,464$ maka dapat diperoleh determinasinya $\mathrm{R} 2$ $=0,215$, yang berarti bahwa penerapan manajemen berbasis sekolah (MBS) memiliki kontribusi sebesar 21,5\% terhadap peningkatan mutu pendidikan di SDIT Al-Haraki.

Keywords: Manajemen Berbasis Sekolah, Mutu Pendidikan, SD Islam Terpadu

\section{Pendahuluan}

Peningkatan mutu sumber daya manusia (SDM) adalah salah satu tema penting dalam pencapaian tujuan pembangunan. Tujuan pembangunan akan tercapai salah satunya apabila di dalamnya terdapat sumber daya manusia yang bermutu sehingga dalam setiap negara terutama negara berkembang peningkatan mutu sumber daya manusia merupakan syarat mutlak yang harus ada. Salah satu wahana yang dapat membantu dalam meningkatkan mutu sumber daya manusia adalah melalui pendidikan karena dengan pendidikan potensi-potensi yang dimiliki oleh manusia dapat diaktualkan dan dikembangkan secara terarah sehingga mutu pendidikan harus senantiasa ditingkatkan.

Dalam Kamus Besar Bahasa Indonesia (KBBI) Online, mutu diartikan sebagai ukuran baik buruk suatu benda, kadar, taraf atau derajat (kepandaian, kecerdasan, dan sebagainya). ${ }^{1}$ Mutu juga dapat diartikan sebagai agregasi karakteristik dari produk atau jasa yang memuaskan bagi konsumen atau pelanggan. Pada mulanya istilah mutu digunakan dalam dunia bisnis namun seiring berjalannya waktu mutu juga digunakan dalam dunia pendidikan. Menurut Dzaujak Ahmad, mutu pendidikan adalah kemampuan sekolah dalam pengelolaan secara professional dan efisien terhadap komponen-komponen yang berkaitan dengan sekolah sehingga menghasilkan nilai tambah terhadap komponen tersebut menurut norma/standar yang berlaku ${ }^{2}$. Sedangkan menurut Oemar Hamalik, pengertian mutu dapat dilihat dari dua sisi, yaitu segi normatif dan segi deskriptif. Dalam artian normatif, mutu ditentukan berdasarkan pertimbangan (kriteria) instrinsik dan ekstrinsik. Berdasarkan kriteria instrinsik, mutu pendidikan merupakan produk pendidikan yakni manusia yang terdidik sesuai dengan standar ideal. Berdasarkan kriteria ekstrinsik, pendidikan merupakan instrument untuk mendidik tenaga kerja yang terlatih. Dalam artian deskriptif, mutu ditentukan berdasarkan keadaan

\footnotetext{
${ }^{1}$ https://kbbi.kemdikbud.go.id/entri/mutu, diakses tanggal 23 Januari 2021.

${ }^{2}$ Dzaujak Ahmad, Penunjuk Peningkatan Mutu Pendidikan di Sekolah Dasar, (Jakarta: Depdikbud, 1996), hal. 8.
} 
senyatanya, misalkan hasil tes prestasi belajar ${ }^{3}$. Dari pendapat tersebut dapat disimpulkan bahwa mutu pendidikan adalah adanya nilai tambah yang terdapat dalam komponen-komponen sekolah menurut standar/norma yang berlaku.

Dalam konteks Indonesia, permasalahan mutu pendidikan masih menjadi pekerjaan rumah bersama mengingat Indonesia masih tertinggal jauh mutu pendidikannya jika dibandingkan dengan negara-negara berkembang lainnya bahkan dengan negara tetangga sendiri seperti Malaysia dan Singapura. Hal ini dibuktikan dengan masih rendahnya kualitas lulusan pendidikan yang ditunjukkan dengan angka pengangguran lulusan pendidikan yang cukup tinggi, masih tingginya tingkat kenakalan remaja sekolah yang ditunjukkan dengan masih seringnya ditemukan kasus tawuran yang terjadi di berbagai daerah, dan masih ditemukannya berbagai kasus kecurangan dalam Ujian Akhir Nasional (UAN).

Berbagai usaha telah dilakukan oleh pemerintah melalui berbagai program dan kebijakan, salah satunya adalah pemberian otonomi kepada setiap satuan pendidikan untuk mengelola secara bebas dan bertanggung jawab dalam melaksanakan program pendidikannya. Pemberian otonomi dalam pengelolaan pendidikan tersebut adalah yang dinamakan manajemen berbasis sekolah (MBS) yang tujuan utamanya adalah tercapainya kualitas pendidikan secara merata yang sesuai dengan kebutuhan masyarakat setempat.

Ada beberapa pendapat para pakar tentang manajemen berbasis sekolah (MBS), di antaranya adalah menurut Mulyasa, Nanang Fatah, dan Bedjo Sudjianto. Mulyasa mengatakan bahwa MBS merupakan salah satu wujud dari reformasi pendidikan yang menawarkan kepada sekolah untuk menyediakan pendidikan yang lebih baik dan memadai bagi para peserta didik $^{4}$. Nanag Fatah mengatakan bahwa MBS merupakan pendekatan politik yang bertujuan untuk mendesain ulang pengelolaan sekolah dengan memberikan kekuasaan kepada kepala sekolah dan meningkatkan partisipasi masyarakat dalam upaya perbaikan kinerja sekolah yang mencakup guru, siswa, komite sekolah, orang tua siswa dan masyarakat. ${ }^{5}$ Sedangkan menurut Bedjo Sudjianto, MBS merupakan model manajemen pendidikan yang memberikan otonomi lebih besar kepada sekolah. Disamping itu, manajemen berbasis sekolah (MBS) juga mendorong pengambilan keputusan partisipatif yang melibatkan langsung semua warga sekolah yang dilayani dengan tetap selaras pada kebijakan nasional pendidikan ${ }^{6}$.

\footnotetext{
${ }^{3}$ Oemar Hamalik, Evaluasi Kurikulum, (Bandung: PT Remaja Rosda Karya, 1990), hal. 33.

24.

${ }^{4}$ E. Mulyasa, Manajemen Berbasis Sekolah, (Bandung: PT Remaja Rosda Karya, 2011), Cet. XIII, hal.

${ }^{5}$ Nanag Fatah, Konsep Manajemen Berbasis Sekolah dan Dewan Sekolah, (Bandung: Pustaka Bani Quraisy, 2003), hal. 8.

${ }^{6}$ Bedjo Sudjianto, Mensiasati Manajemen Berbasis Sekolah di Era Krisis yang Berkepanjangan, (Jakarta: ICW, 2004), hal. 25.
} 
Dari beberapa pendapat tersebut dapat ditarik sebuah kesimpulan bahwa manajemen berbasis sekolah adalah sebuah kebijakan otonomisasi pengelolaan pendidikan kepada setiap satuan pendidikan untuk menyediakan pendidikan yang lebih baik dan memadai bagi peserta didik dengan melibatkan semua warga sekolah agar sesuai dengan tuntutan masyarakat setempat dan tetap memperhatikan keselarasan pada kebijakan nasional pendidikan.

Manajemen berbasis sekolah atau istilah dalam Bahasa Inggrisnya adalah School Based Management secara historis pertama kali muncul di Amerika Serikat pada tahun 1960 hingga tahun 1990-an sebagai imbas dari adanya berbagai pertanyaan masyarakat tentang relevansi pendidikan dengan tuntutan dan perkembangan masyarakat setempat yang selama ini diabaikan oleh dunia pendidikan. Sedangkan di Indonesia, istilah manajemen berbasis sekolah (MBS) baru dikenal sekitar tahun 1999/2000 yang ditandai dengan adanya peluncuran program Bantuan Operasional Manajemen Mutu (BOMM). Program Bantua Operasional Manajemen Mutu (BOMM) kemudian dirubah menjadi Dana Rintisan untuk MPMBS, dimana program ini sejalan dengan implementasi Undang-undang No. 25 tahun 2000 tentang Propenas. Dalam undang-undang tersebut dikatakan bahwa manajemen berbasis sekolah (MBS) dimaksudkan sebagai upaya untuk meningkatkan kemandirian sekolah dalam penyelenggaraan pendidikan.

Sebagai usaha dalam meningkatkan kualitas pendidikan, manajemen berbasis sekolah (MBS) memiliki beberapa karakter penting yang harus diperhatikan oleh setiap sekolah yang akan menerapkannya. Di antara karakter-karakter manajemen berbasis sekolah (MBS) adalah adanya keseragaman dalam pola penggajian guru, otonomi manajemen sekolah, pemberdayaan guru secara optimal, pengelolaan sekolah secara partisipatif, sistem yang didesenteralisasikan, sekolah dengan pilihan atau otonomi sekolah dalam menentukan aneka pilihan, hubungan kemitraan (partnership) antara dunia bisnis dan dunia pendidikan, akses terbuka bagi sekolah untuk tumbuh relatif mandiri, dan pemasaran sekolah secara kompetitif ${ }^{7}$.

Adapun komponen-komponen yang terdapat dalam manajemen berbasis sekolah (MBS) di antaranya adalah manajemen kurikulum dan program pengajaran, manajemen tenaga pendidik dan kependidikan, manajemen kesiswaan, manajemen keuangan dan pembiayaan, manajemen sarana dan prasarana, manajemen hubungan sekolah dengan masyarakat, dan manajemen pemasaran dan layanan khusus. Komponen-komponen inilah yang menjadi inti yang paling penting daripada manajemen berbasis sekolah (MBS). Untuk dapat mengimplementasikan manajemen berbasis sekolah (MBS) secara efektif dan efisien, maka

$$
30 .
$$

${ }^{7}$ Sudarwan Danim, Visi Baru Manajemen Sekolah, (Jakarta: PT Bumi Aksara, 2012), Cet. IV, hal. 29-

46 | IQ (Ilmu Al-qur'an): Jurnal Pendidikan Islam | Volume 4 No.01 2021, 43-50 
kepala sekolah harus memiliki kemampuan kepemimpinan, perencanaan dan pandangan yang luas tentang sekolah dan pendidikan. Di samping itu, kepala sekolah juga harus melakukan sharing atau diskusi dengan para pakar baik di forum-forum formal maupun non formal, dan studi banding agar memiliki gambaran dalam merencanakan manajemen berbasis sekolah (MBS). Dalam manajemen berbasis sekolah (MBS), kepala sekolah juga dituntut agar mampu melaksanakan fungsinya sebagai manajer sekolah, yaitu melakukan pengawasan kelas, membina, dan memberikan saran-saran positif kepada guru.

Penerapan atau implementasi manajemen berbasis sekolah (MBS) memang bukanlah hal yang sangat mudah untuk dilakukan mengingat otonomisasi dalam dunia pendidikan adalah perkara yang relatif baru sehingga memerlukan usaha yang sungguh-sungguh dan strategi yang tepat dan jitu. Meskipun penerapan atau implementasi manajemen berbasis sekolah (MBS) bukanlah perkara mudah namun indikator-indikatornya dapat dilihat dari beberapa hal, yaitu adanya orientasi ke arah efektivitas pembelajaran, kepemimpinan kepala sekolah yang efektif, pengelolaan tenaga pendidik dan kependidikan secara berdaya guna, sekolah memiliki budaya mutu yang tinggi, sekolah memiliki kemandirian, partisipasi semua warga sekolah sangat tinggi, transparansi dalam pengambilan kebijakan, keuangan, dan ketercapaian program sekolah, sekolah responsit terhadap kebutuhan dan perkembangan peserta didik dan masyarakat, memiliki akuntabilitas, dan adanya kepuasan semua warga sekolah.

Sebagaiman yang telah disinggung di atas bahwa manajemen berbasis sekolah (MBS) adalah usaha yang dilakukan dalam rangka meningkatkan mutu pendidikan sehingga manajemen berbasis sekolah memiliki kaitan dengan kualitas pendidikan. Sekolah Dasar Islam Terpadu (SDIT) Al- Haraki Kota Depok adalah salah satu sekolah dasar Islam swasta yang dalam pengelolaan pendidikannya menerapkan manajemen berbasis sekolah (MBS). Dalam tulisan ini akan dipaparkan hasil penelitian tentang pengaruh penerapan manajemen berbasis sekolah (MBS) terhadap mutu pendidikan di SDIT Al-Haraki Kota Depok.

\section{Metode Penelitian}

Metode yang digunakan dalam penelitian ini adalah kuantitatif, dimana data yang diperoleh berupa angka dan analisisnya menekankan pada numerikal yang diolah dengan statistika. Pendekatan yang digunakan dalam penelitian ini adalah pendekatan korelasional yang bertujuan untuk melihat pengaruh antara penerapan manajemen berbasis sekolah terhadap kualitas pendidikan. Adapun data yang diperoleh merupakan hasil penyebaran angket kepada 46 guru di SDIT Al- Haraki Kota Depok, selain itu juga wawancara dengan kepala sekolah dan dokumentasi sebagai data pendukung. Dalam penelitian ini terdiri dari dua variabel yang 
dijadikan acuan, yaitu variabel manajemen berbasis sekolah $(\mathrm{X})$ dan variabel mutu pendidikan (Y).

\section{Hasil Penelitian dan Pembahasan}

Deskripsi data yang disajikan dari hasil penelitian ini adalah untuk memberikan gambaran secara umum mengenai penyebaran data yang diperoleh di lapangan. Data yang dikumpulkan dalam penelitian ini terdiri dari dua variabel, yaitu manajemen berbasis sekolah (X) dan mutu pendidikan (Y) dan data ini diperoleh melalui angket (kuisioner) yang disebarkan kepada 46 guru SDIT Al-Haraki Kota Cirebon. Berdasarkan data manajemen berbasis sekolah yang berhasil dikumpulkan dari responden didapatkan mean (rata-rata hitung) 125,39, median 127, dan modus 130. Dari kecenderungan penyebaran data didapatkan rentangan 62 dan simpangan baku 12,587. Nilai mean 125,39 tersebut adalah setara dengan 41,3\% kemungkinan skor tertinggi karena itu dapat disimpulkan bahwa secara rata-rata skor manajemen berbasis sekolah di SDIT Al-Haraki relatif cukup baik. Adapun rentangan dan simpangan baku yang relative besar menunjukkan cukup heterogennya skor manajemen berbasis sekolah.

Selanjutnya dilakukan pengklasifikasian dengan menggunakan cut of point. Karena data sampel berdistribusi normal, maka cut of point-nya menggunakan mean, yaitu 125,39. Jika skor manajemen berbasis sekolah di atas atau sama dengan 125,39 maka dikategorikan baik sebaliknya jika skor manajemen berbasis sekolah di bawah 125,39 maka dikategorikan kurang baik. Dan berdasarkan data dari distribusi frekuensi didapatkan bahwa manajemen berbasis sekolah menurut para guru SDIT Al-Haraki Kota Depok yang dinyatakan baik sebesar 57\% dan dinyatakan kurang baik sebesar 43\%. Dengan demikian, secara deskriptif dapat dilihat bahwa manajemen berbasis sekolah di SDIT Al-Haraki Kota Depok berada dalam kategori cukup baik.

Hipotesis yang diujikan dalam penelitian ini menyatakan bahwa terdapat pengaruh manajemen berbasis sekolah (X) terhadap mutu pendidikan (Y). Analisis regresi linear sederhana terhadap data penelitian manajemen berbasis sekolah terhadap mutu pendidikan menghasilkan koefisien arah b sebesar 56,766 dan konstanta a sebesar 0,479. Demikian itu bentuk hubungan antara kedua variabel tersebut dapat disajikan oleh persamaan:

$$
\hat{\mathbf{Y}}=\mathbf{5 6 , 7 6 6}+\mathbf{0 , 4 7 9} \mathrm{X}
$$

Persamaan tersebut dapat diartikan bahwa apabila skor manajemen berbasis sekolah (X) naik satu poin atau satu skor, maka akan diikuti oleh kenaikan mutu pendidikan (Y) sebesar 0,479 poin dan untuk mengetahui derajat signifikansinya, maka persamaan regresi tersebut selanjutnya diuji dengan menggunakan uji-F. Berdasarkan hasil uji-F diperoleh nilai $\mathrm{p}($ sig.) $=$ 48 | IQ (Ilmu Al-qur'an): Jurnal Pendidikan Islam| Volume 4 No.01 2021, 43-50 
0,000, nilai ini lebih kecil dari 5\% maka hipotesis nol ditolak, hal ini menunjukkan bahwa koefisien regresi tersebut sangat signifikan. Selanjutnya analisis korelasi antara manajemen berbasis sekolah dengan mutu pendidikan diperoleh nilai koefisien korelasi r product moment sebesar 0,464 dan telaah signifikansi terhadap nilai koefisien korelasi tersebut diperoleh nilai $\mathrm{p}=0,000$. Karena nilai $\mathrm{p}<5 \%$ berarti hipotesis nol ditolak. Hal ini menunjukkan bahwa nilai koefisien korelasi antara manajemen berbasis sekolah dengan mutu pendidikan adalah signifikan, artinya terdapat hubungan positif dan erat antara manajemen berbasis sekolah dengan mutu pendidikan di SDIT Al-Haraki Kota Depok.

Selanjutnya karena koefisien korelasi $\mathrm{r}=0,464$ maka dapat diperoleh determinasinya $\mathrm{R}^{2}=0,215$, yang berarti bahwa $21,5 \%$ variansi mutu pendidikan dapat dijelaskan oleh manajemen berbasis sekolah melalui persamaan regresi:

$$
\hat{\mathbf{Y}}=\mathbf{5 6 , 7 6 6}+\mathbf{0 , 4 7 9} \mathrm{X}
$$

Dengan kata lain kontribusi manajemen berbasis sekolah terhadap mutu pendidikan di SDIT Al-Haraki Kota Depok sebesar 21,5\% sedangkan sisanya 78,5\% oleh faktor lainnya. Oleh karena nilai $\mathrm{p}$ (sig.) $=0,000$ lebih kecil dari 5\% maka hipotesis nol ditolak, hal ini berarti bahwa manajemen berbasis sekolah berpengaruh secara positif dan signifikan terhadap mutu pendidikan di SDIT Al-Haraki. Dengan demikian, dapat disimpulkan bahwa apabila manajemen berbasis sekolah diterapkan maka dapat diramalkan mutu pendidikan akan meningkat. Sebaliknya apabila manajemen berbasis sekolah tidak diterapkan maka dapat diramalkan mutu pendidikan akan menurun.

Hasil ini konsisten dengan teori bahwa manajemen berbasis sekolah (MBS) bertujuan mencapai mutu quality dan relevansi pendidikan yang setingi-tingginya ${ }^{8}$. Dengan demikian, untuk meningkatkan mutu pendidikan maka dapat dilakukan dengan cara menerapkan manajemen berbasis sekolah.

\section{Kesimpulan}

Peningkatan mutu pendidikan adalah merupakan keharusan bagi setiap lembaga pendidikan bahkan pendidikan yang bermutu adalah salah satu wahana yang dapat meningkatkan mutu sumber daya manusia, yang dimana sumber daya manusia yang bermutu dapat membantu pembangunan nasional. Salah satu cara yang dapat dilakukan untuk meningkatkan mutu pendidikan adalah melalui manajemen berbasis sekolah, dimana dalam manajemen berbasis sekolah setiap satuan pendidikan diberikan kewenangan penuh untuk mengelola dan menyelenggarakan program pendidikannya yang melibatkan semua unsur

${ }^{8}$ Umaidi, Manajemen Berbasis Sekolah, (Jakarta: CEQM, 2004), hal. 35. 


\section{Abu Maskur}

sekolah dan disesuaikan dengan kebutuhan dan perkembangan masyarakat. Sekolah Dasar Islam Terpadu (SDIT) Al- Haraki Kota Depok adalah salah satu sekolah Islam swasta yang menerapkan manajemen berbasis sekolah dalam penyelenggaraan pendidikannya dan berdasarkan hasil penelitian yang telah dilakukan didapatkan sebuah kesimpulan bahwa penerapan manajemen berbasis sekolah berpengaruh secara positif dan signifikan terhadap mutu pendidikan di SDIT Al- Haraki Kota Depok sehingga apabila manajemen berbasis sekolah diterapkan dan ditingkatkan maka mutu pendidikan di SDIT Al- Haraki akan semakin meningkat.

\section{Daftar Pustaka}

Ahmad, Dzaujak. 1996. Penunjuk Peningkatan Mutu Pendidikan di Sekolah Dasar. Jakarta: Depdikbud.

Danim, Sudarwan. 2012. Visi Baru Manajemen Sekolah. Jakarta: PT Bumi Aksara.

E. Mulyasa. 2011. Manajemen Berbasis Sekolah. Bandung: PT Remaja Rosda Karya. Cet. XIII. Fatah, Nanang. 2003. Konsep Manajemen Berbasis Sekolah dan Dewan Sekolah. Bandung: Pustaka Bani Quraisy.

Hamalik, Oemar. 1990. Evaluasi Kurikulum. Bandung: PT Remaja Rosda Karya.

Sudjianto, Bedjo. 2004. Mensiasati Manajemen Berbasis Sekolah di Era Krisis Yang Berkepanjangan. Jakarta: ICW.

Umaidi. 2004. Manajemen Berbasis Sekolah. Jakarta: CEQM.

https://kbbi.kemdikbud.go.id/entri/mutu, diakses tanggal 23 Januari 2021. 